\title{
Home Mechanical Ventilation: A 12-Year Population-Based Retrospective Cohort Study
}

\author{
Marcus Povitz MD MSc FRCPC, Louise Rose RN PhD, Salimah Z Shariff PhD, Sean Leonard, \\ Blayne Welk MD MSc, Krista Bray Jenkyn PhD, David J Leasa MD, and \\ Andrea S Gershon MD MSc
}

\begin{abstract}
BACKGROUND: Increasing numbers of individuals are being initiated on home mechanical ventilation, including noninvasive (bi-level) and invasive mechanical ventilation delivered via tracheostomy due to chronic respiratory failure to enable symptom management and promote quality of life. Given the high care needs of these individuals, a better understanding of the indications for home mechanical ventilation, and health-care utilization is needed. METHODS: We performed a retrospective cohort study using provincial health administrative data from Ontario, Canada (population $\sim 13,000,000)$. Home mechanical ventilation users were characterized using health administrative data to determine the indications for home mechanical ventilation, the need for acute care at the time of ventilation approval, and their health service use and mortality rates following approval. RESULTS: The annual incidence of home mechanical ventilation approval rose from $1.8 / 100,000$ in 2000 to $5.0 / 100,000$ in 2012 , or an annual increase of approximately $0.3 / 100,000$ persons/y. The leading indications were neuromuscular disease, thoracic restriction, and COPD. The indication for the remainder could not be determined due to limitations of the administrative databases. Of the 4,670 individuals, 23.0\% commenced home mechanical ventilation following an acute care hospitalization. Among individuals who survived at least $1 \mathrm{y}$, fewer required hospitalization in the year that followed home mechanical ventilation approval $(29.9 \%$ vs $39.8 \%)$ as compared with the year prior. CONCLUSIONS: Utilization of home mechanical ventilation is increasing in Ontario, Canada, and further study is needed to clarify the factors contributing to this and to further optimize utilization of health-care resources. Key words: home mechanical ventilation; chronic respiratory failure; health administrative data. [Respir Care 2018;63(4):380-387. (C) 2018 Daedalus Enterprises]
\end{abstract}

\section{Introduction}

Recent guidelines recommend the use of either invasive or noninvasive ventilation (NIV) as home mechan-

Drs Povitz and Leasa are affiliated with the Department of Medicine and Dr Povitz is also affiliated with the Department of Epidemiology and Biostatistics, Schulich School of Medicine and Dentistry, Western University, London, Ontario, Canada. Dr Shariff, Mr Leonard, Dr Welk, and Dr Jenkyn are affiliated with the Institute for Clinical Evaluative Sciences, London, Ontario, Canada. Dr Welk is also affiliated with the Department of Surgery, Schulich School of Medicine and Dentistry, Western University, London, Ontario, Canada. Dr Rose is affiliated with the Department of Critical Care Medicine, Sunnybrook Health Sciences Centre, the Lawrence S Bloomberg Faculty of Nursing and Interdepartmental Division of Critical Care Medicine, University of Toronto, the Provincial Centre of Weaning Excellence, Michael Garron Hospital, and the Institute for Clinical Evaluative Sciences, Toronto, Ontario, Canada. ical ventilation for treatment of chronic respiratory failure. ${ }^{1-4}$ Home mechanical ventilation has been shown to be effective in prolonging life and improving healthrelated quality of life. ${ }^{5}$ Given the expanding use of home mechanical ventilation, a better understanding of the

\footnotetext{
Dr Gershon is affiliated with the Institute for Clinical Evaluative Sciences, the Department of Medicine, Sunnybrook Health Sciences Centre, and the Department of Medicine, University of Toronto, Toronto, Ontario, Canada.

This study was supported by the Institute for Clinical Evaluative Sciences (ICES) Western site. ICES is funded by an annual grant from the Ontario Ministry of Health and Long-Term Care (MOHLTC). Core funding for ICES Western is provided by the Academic Medical Organization of Southwestern Ontario (AMOSO), the Schulich School of Medicine and Dentistry (SSMD), Western University, and the Lawson Health Research Institute (LHRI). The opinions expressed in this document are solely
} 
profile of individuals using it and the impact on the health-care system is needed.

See the Related Editorial on Page 491

A growing body of scientific evidence supports the provision of home mechanical ventilation for life extension in neuromuscular conditions causing respiratory failure, such as amyotrophic lateral sclerosis (ALS), ${ }^{6}$ muscular dystrophy, ${ }^{7}$ and other less common neuromuscular diseases. ${ }^{1}$ For such patients, ventilation has also been shown to improve health-related quality of life $\mathrm{e}^{6,8}$ and reduce symptoms related to chronic respiratory failure, such as dyspnea, daytime sleepiness, and fatigue. Home mechanical ventilation for neuromuscular and chest wall disease has been shown to reduce the frequency of emergency department visits and hospital admission. ${ }^{5}$ Studies also support ventilation for obesityhypoventilation syndrome to lower the risk of death, ${ }^{9}$ improve daytime sleepiness ${ }^{10}$ and quality of life, as well as to lower health-care utilization. ${ }^{11}$ Home mechanical ventilation for lung disease, such as COPD, remains controversial, ${ }^{12,13}$ although it may be used to reduce hospitalizations ${ }^{14}$ or as a bridge to transplantation. Additionally, home mechanical ventilation may be used to facilitate discharge from hospital and to prevent individuals from needing ongoing institutional care, so that they may preserve their independence. ${ }^{1,3}$

Various regional and national approaches to the delivery of community support services for home mechanical ventilation have been developed both within Canada and internationally with substantial variation in the types of patients receiving it as well as the level and type of service provision. ${ }^{4,15-18}$ Although the benefits of home mechanical ventilation to the individual, their family members, and the health-care system are relatively undisputed, the optimal way to support individuals to live at home and to reduce avoidable acute care utilization remains unknown. One comparison of 2 systems showed divergence in the characteristics of home mechanical ventilation users and of the service provision; however, quality of life was not different. ${ }^{18}$ Describing the characteristics of home mechanical ventilation recipients and improving the understanding of service provision to them is the first step in establishing their needs and improving health-care delivery and outcomes.

those of the authors and do not represent an endorsement by or the views of the United States Air Force, the Department of Defense, or the United States Government. The authors have disclosed no conflicts of interest.

Correspondence: Marcus Povitz MD MSc FRCPC, London Health Sciences Centre, 800 Commissioners Road East, Room E6-202, London, Ontario N6A 5W9, Canada. E-mail: marcus.povitz@1hsc.on.ca.

DOI: $10.4187 /$ respcare.05689

\section{QUICK LOOK}

\section{Current knowledge}

Previous studies of home mechanical ventilation have described the prevalence of and indications for home mechanical ventilation. These measures vary widely among industrialized nations and even between regions in the same country. These reports are based on surveys of referral centers and may not represent the population.

\section{What this paper contributes to our knowledge}

We used provincial health administrative databases to identify first time users of home mechanical ventilation and determine the incidence per year. We describe the leading indications for mechanical ventilation. We also determined health-care utilization changes and describe the mortality rates of individuals using home mechanical ventilation.

Previous studies have used surveys ${ }^{15,16,19,20}$ to describe the prevalence and characteristics of home mechanical ventilation users and their utilization of the health-care system. These surveys, however, may underestimate the frequency of home mechanical ventilation initiation by relying on volunteer reporting and do not provide information about changes over time given their cross-sectional nature. Therefore, our primary objective was to examine the incidence of home mechanical ventilation at a populationbased level in Ontario, Canada, over a 12-y time frame. Secondary objectives included describing the indications for home mechanical ventilation, trends in 1- and 3-y mortality, and their health-care utilization before and after initiation of home mechanical ventilation.

\section{Methods}

\section{Study Description}

We conducted a retrospective population-based cohort study to characterize home mechanical ventilation users in Ontario, the largest province of Canada, with a population of approximately 13 million individuals.

We conducted our study according to a prespecified protocol approved by the research ethics board at Sunnybrook Health Sciences Centre (Toronto, Ontario), and reporting of the study followed guidelines for observational studies using routinely collected health data. ${ }^{21}$

\section{Data Sources}

Ontario has a universal, publicly funded, single-payer health-care system with health-care data housed in large population-based health administrative databases. Relevant 
data sets were linked using unique encoded identifiers and analyzed at the Institute for Clinical Evaluative Sciences. Individuals with an approved request for equipment for home mechanical ventilation, which includes ventilators capable of either invasive or noninvasive ventilation, were identified from the Assistive Devices Program database, a database that contains approvals for various assistive devices, including ventilators. All individuals in Ontario residing outside a hospital or chronic care facility with a clinically recognized need for home mechanical ventilation are eligible to receive equipment and related consumables when requested by an eligible health-care provider and subsequently approved by the Ministry of Health and Long Term Care. Additional information on these individuals was obtained from the following databases: the Ontario Health Insurance Plan, which contains all billing for physician services, including those for procedures; the Discharge Abstract Database, which contains all data on demographic and clinical information and responsible diagnoses for all hospitalizations; the National Ambulatory Care Reporting System, which contains all emergency department visits, ambulatory $1-\mathrm{d}$ surgeries, and select ambulatory clinics (eg, dialysis); the Registered Persons Database, which contains demographic data, including death outside of a hospital setting; the Continuing Care Reporting System, which contains data on facility-based continuing (residential) care services; the National Rehabilitation Reporting System, which contains data on in-patient rehabilitation programs; and the Home Care Database, which contains data about provincially funded home care use. Diagnoses in the databases are documented using the International Classification of Disease 9th Revision (before 2002) or 10th Revision (after 2002) or database-specific codes. Intercensal populations were estimated using data from the Ontario Ministry of Health and LongTerm Care: IntelliHEALTH ONTARIO.

\section{Participants}

Inclusion Criteria We obtained all records of ventilator equipment and supplies from the Assistive Devices Program database. Individuals were included in the cohort if a request for a ventilator (capable of either invasive or noninvasive ventilation) was submitted and approved between April 1, 2000, and March 31, 2013, and they were $\geq 18 \mathrm{y}$ of age on the approval date. We defined the index date as the home mechanical ventilation approval date from the Assistive Devices Program database. Individuals started on home mechanical ventilation with equipment loaned from another provider or purchased privately or started on acute care ventilation during a hospitalization could not be identified. We used procedural codes for tracheotomy in the $5 \mathrm{y}$ before the Assistive Devices Program approval date as a surrogate for individuals receiving invasive ventilation, as we could not distinguish applications for NIV from those for invasive ventilators. We did not consider devices typically used to treat sleep apnea, namely CPAP or bi-level positive airway pressure devices incapable of providing a backup rate as mechanical ventilation.

Exclusion Criteria Individuals were excluded if the Assistive Devices Program database indicated that they were long-term care residents. Additional exclusion criteria comprised records with invalid/inaccurate information, such as an invalid health card number, age missing or $>105 \mathrm{y}$, sex missing, death date recorded before signed consent for a ventilator, and not being an Ontario resident when their ventilator was approved. In cases where multiple request records were noted, we restricted inclusion to the first record for that individual (assumed to be the first/incident application).

Cohort Characteristics For all included individuals, we determined age, sex, and rural residence at the time of home mechanical ventilation approval. Neighborhood income quintiles were determined based on home address and an algorithm from Statistics Canada. ${ }^{22}$ We determined the CharlsonDeyo comorbidity score to establish the overall burden of other medical conditions. ${ }^{23}$ The Charlson-Deyo score is a composite of 19 common comorbidities, ${ }^{24}$ which is used to predict mortality ${ }^{24}$ and health-care utilization. ${ }^{25}$ Home mechanical ventilation users who did not have any hospitalizations were assigned a score of zero. We identified COPD, asthma, and congestive heart failure as comorbidities using validated algorithms, ${ }^{26-28}$ given that they may have contributed to the need for home mechanical ventilation, but did not consider them the primary indication if other conditions were present, since Canadian guidelines do not support use of home mechanical ventilation for these conditions, ${ }^{1}$ and we could not determine the severity of disease.

\section{Incidence of Home Mechanical Ventilation}

The incidence of home mechanical ventilation was defined as the number of new home mechanical ventilation approvals per 100,000 adults in Ontario per fiscal year.

\section{Primary Indication for Home Mechanical Ventilation}

As the Assistive Devices Program database does not include the indication for home mechanical ventilation, we used health administrative databases to identify potential primary indications for ventilation. A priori, we identified the following list of potential indications: thoracic cage restriction disease (kyphoscoliosis, fibrothorax, thoracoplasty, obesity, thoracic resection) and neuromuscular disease (ALS, muscular dystrophy, diaphragmatic paralysis, myasthenia gravis, Guillain-Barré syndrome, spinal cord injury, stroke/transient ischemic attack, multiple sclerosis, Parkinson's disease, neuropathy, post-polio syndrome, 
spina bifida, spinal muscular atrophy). We sought diagnostic codes from hospitalizations in the year preceding home mechanical ventilation approval. We also searched for diagnoses from physician billing, rehabilitation, and chronic care admissions during this time.

\section{Urgency of Home Mechanical Ventilation Initiation}

We identified patients who were hospitalized in the month before home mechanical ventilation approval and determined whether they received critical care services and/or mechanical ventilation. ${ }^{29}$

\section{Health-Care Utilization}

We compared health-care utilization in the year before initiation of home mechanical ventilation with the year following approval excluding the $30 \mathrm{~d}$ before and $30 \mathrm{~d}$ following approval, given the increased utilization related to initiation of home mechanical ventilation, which might bias the results of a pre/post comparison. We restricted this analysis to users who survived at least $1 \mathrm{y}$ to ensure that information was available for the complete period. We considered that inclusion of users who died before the full year would bias results, given censoring of the health-care utilization due to death. Specifically, we looked at hospitalizations, emergency department visits, and out-patient respirology/pulmonary medicine and out-patient neurology specialist physician visits identified using specialty-specific billing codes.

\section{Mortality After Home Mechanical Ventilation}

We determined the 1- and 3-y mortality rate per 100 individuals following the initiation of home mechanical ventilation. We stratified by age groups $18-39,40-64$, and $65 \mathrm{y}$ and older, given the anticipated higher mortality in older individuals.

\section{Analysis}

We reported continuous variables as means and SD or medians and interquartile ranges where appropriate. Categorical variables were reported as frequencies and proportions and were compared using chi-square tests. For health-care utilization, we compared frequency of health service use before and after home mechanical ventilation initiation using the Fisher exact test. Results were reported with $95 \% \mathrm{CI}$ and $P$ values where appropriate. We used linear regression to determine the mean rate of increase in incidence of home mechanical ventilation per year and used the Cochran-Armitage test to examine change over time. All statistical tests were completed using Stata release 13 (StataCorp, College Station, Texas) and SAS for UNIX version 9.3 (SAS Institute, Cary, North Carolina).

\section{Results}

\section{Cohort Characteristics}

We identified 4,670 individuals approved for home mechanical ventilation from April 1, 2000, to March 31, 2013 (fiscal years 2000-2012). Characteristics of these subjects are shown in Table 1. The incidence of approvals increased from 1.8 per 100,000 adults in 2000 to 5.0 per 100,000 adults in 2012 (Fig. 1). This is equivalent to a mean increase of $0.3 / 100,000$ (95\% CI 0.2/100,000 to $0.4 / 100,000$ ). At least one neuromuscular disease or thoracic cage disorder was identified for $44.9 \%$ of individuals. The most frequent neurological conditions were ALS (7.5\%) and muscular dystrophy $(6.8 \%)$. Of thoracic cage restriction conditions, obesity was the most common, affecting $15.9 \%$ individuals. COPD, congestive heart failure, and asthma were found in $31.3,22.6$, and $13.0 \%$ of the cohort as a whole, but COPD without other potential indications was found in $18.8 \%$ of the cohort. Almost $8 \%$ of individuals had undergone tracheostomy before home mechanical ventilation approval, indicating the need for invasive ventilation. Over the course of the study period, the proportion of new users who had undergone tracheotomy ranged from $12.2 \%$ in 2000 to $6.3 \%$ in 2011 with a significant decline annually in the proportion of invasively ventilated individuals $(P=.01)$.

\section{Urgency of Home Mechanical Ventilation Initiation}

Twenty-three percent of individuals were hospitalized in the $30 \mathrm{~d}$ before home mechanical ventilation approval. Of these, $100 \%$ required ICU admission and $72.5 \%$ received mechanical ventilation in hospital. The median (interquartile range) hospital stay was 15 (7-36) d. The remaining $77.0 \%$ had no acute care hospital stay within $30 \mathrm{~d}$ of approval and therefore commenced home mechanical ventilation in an out-patient setting.

\section{Health-Care Utilization}

Of the 4,670 individuals approved for home mechanical ventilation, $75.3 \%$ survived to $1 \mathrm{y}$ and were included in our analysis of health-care utilization. Overall, fewer individuals were hospitalized in the year following home mechanical ventilation approval compared with the year prior $(29.9 \%$ vs $39.8 \%, P<.001$ ), excluding the $30 \mathrm{~d}$ immediately before and after home mechanical ventilation approval. The proportion requiring at least one emergency department visit decreased from 1,998/3,517 (56.8\%) in the year before home mechanical ventilation approval to $1,725 / 3,517$ (49.0\%) following approval $(P<.001)$. In contrast, the number of individuals using home care services increased from $32.9 \%$ in the year before home mechanical ventilation approval to $43.9 \%$ in the 12 months after 
Table 1. Characteristics Home Mechanical Ventilation Users in Ontario, Canada, 2000-2012

\begin{tabular}{|c|c|}
\hline Demographic Characteristics $(N=4,670)$ & Values \\
\hline Age, mean $\pm \mathrm{SD}$ y & $58.5 \pm 14.6$ \\
\hline Male sex, $\%$ & 59.7 \\
\hline Tracheotomy, \%* & 7.7 \\
\hline \multicolumn{2}{|l|}{ Neighborhood income quintile, $\%$} \\
\hline 1 (lowest) & 22.9 \\
\hline 2 & 20.0 \\
\hline 3 & 18.7 \\
\hline 4 & 19.2 \\
\hline 5 (highest) & 18.7 \\
\hline Data not available & 0.5 \\
\hline Rural residence, $\%$ & 15.8 \\
\hline Charlson comorbidity score, median (IQR) & $1(0-2)$ \\
\hline \multicolumn{2}{|l|}{ Indication for $\mathrm{HMV}, \% \dagger$} \\
\hline \multicolumn{2}{|l|}{ Thoracic cage abnormalities } \\
\hline Kyphoscoliosis & 1.1 \\
\hline Fibrothorax & 2.5 \\
\hline Thoracoplasty & $\leq 0.2$ \\
\hline Thoracic resection & 0.3 \\
\hline Obesity & 15.9 \\
\hline \multicolumn{2}{|l|}{ Neuromuscular conditions } \\
\hline Amyotrophic lateral sclerosis & 7.5 \\
\hline Muscular dystrophy & 6.8 \\
\hline Diaphragm paralysis & 0.8 \\
\hline Myasthenia gravis & 6.3 \\
\hline Guillain-Barré & $\leq 0.2$ \\
\hline Spinal cord injury & 5.3 \\
\hline Stroke/transient ischemic attack & 1.1 \\
\hline Multiple sclerosis & 2.8 \\
\hline Parkinson's disease & 1.0 \\
\hline Neuropathy & 0.8 \\
\hline Cerebral palsy & 4.0 \\
\hline Post-polio syndrome & $\leq 0.2$ \\
\hline Spina bifida & 0.5 \\
\hline Spinal muscular atrophy & $\leq 0.2$ \\
\hline Other neuromuscular disorders & 0.4 \\
\hline COPD without other indication & 18.8 \\
\hline Unknown indication, \% & 36.2 \\
\hline \multicolumn{2}{|l|}{ Urgency of HMV initiation, $n(\%)$} \\
\hline $\begin{array}{l}\text { Urgent with hospitalization within } 30 \mathrm{~d} \text { before } \\
\text { HMV approval }\end{array}$ & $1,074(23.0)$ \\
\hline Invasively ventilated & $779(16.9)$ \\
\hline $\begin{array}{l}\text { Non-urgent initiating HMV in an out-patient } \\
\text { setting }\end{array}$ & $3,596(77.0)$ \\
\hline \multicolumn{2}{|c|}{$\begin{array}{l}\text { * Surrogate for invasive ventilation. } \\
\dagger \text { Indications were not mutually exclusive; percentage of total cohort reported. } \\
\mathrm{IQR}=\text { interquartile range } \\
\mathrm{HMV}=\text { home mechanical ventilation }\end{array}$} \\
\hline
\end{tabular}

$(P<.001)$. Respirology/pulmonology out-patient visits increased from $41.9 \%$ in the year before home mechanical ventilation approval to $47.0 \%$ in the year after $(P<.001)$, whereas neurology out-patient visits dropped from $21.8 \%$ in the year before to $19.8 \%$ in the year after $(P=.02)$ (Fig. 2).

\section{Mortality After Home Mechanical Ventilation}

Crude 1- and 3-y mortality rates remained largely stable from 2000 to 2012 and increased by age strata. The only significant change observed during the study period was in 1-y mortality in 40-64-y-old subjects (Table 2).

\section{Discussion}

We conducted a 12-y retrospective cohort study of home mechanical ventilation users using administrative data and found that the incidence of home mechanical ventilation approval almost tripled. Only a minority required invasive ventilation, and few were hospitalized in the $30 \mathrm{~d}$ before the approval of home mechanical ventilation, suggesting that most were identified and initiated in out-patient settings. We found for individuals that survived for 12 months after home mechanical ventilation approval that the overall proportion of hospitalizations and emergency department visits declined significantly, comparing the 12 months before and 12 months after approval, whereas home care use and respiratory specialist out-patient visits increased. Mortality among these subjects was largely unchanged.

The reason for the increased incidence of home mechanical ventilation over time (from $1.8 / 100,000$ in 2000 to $5.0 / 100,000$ in 2012) is probably multifactorial; however, due to the limited information available from health administrative databases, we can only speculate on the reasons. One reason may be the steadily rising prevalence of obesity in Canada. ${ }^{30}$ Another might be the development of specialized centers and physician leaders who can influence the overall attitudes toward provision of home mechanical ventilation and increase incidence rates. ${ }^{31} \mathrm{~A}$ now dated European survey reported a European prevalence of 6.6/100,000, although this varied from 0.1 in Poland to $9.6 / 100,000$ in Denmark, and reported that the indication for mechanical ventilation varied widely between countries. ${ }^{15}$ This survey also showed no consistency in the proportion of individuals receiving invasive ventilation, although it was highest for those with a neuromuscular indication. A more recent Canadian survey reported a prevalence of 12.9/100,000 and reported that more than half of individuals had neuromuscular disease, with lung disease representing $<5.0 \% .{ }^{16}$ Neither reported the incidence of home mechanical ventilation use to provide data comparable with our findings. Conversely, we were unable to report on prevalence, as administrative databases did not enable us to determine those individuals who had discontinued home mechanical ventilation.

Many incident cases were not hospitalized in the $30 \mathrm{~d}$ before home mechanical ventilation approval and were therefore initiated on therapy in another setting. Home-based and polysomnographic home mechanical ventilation starts have 


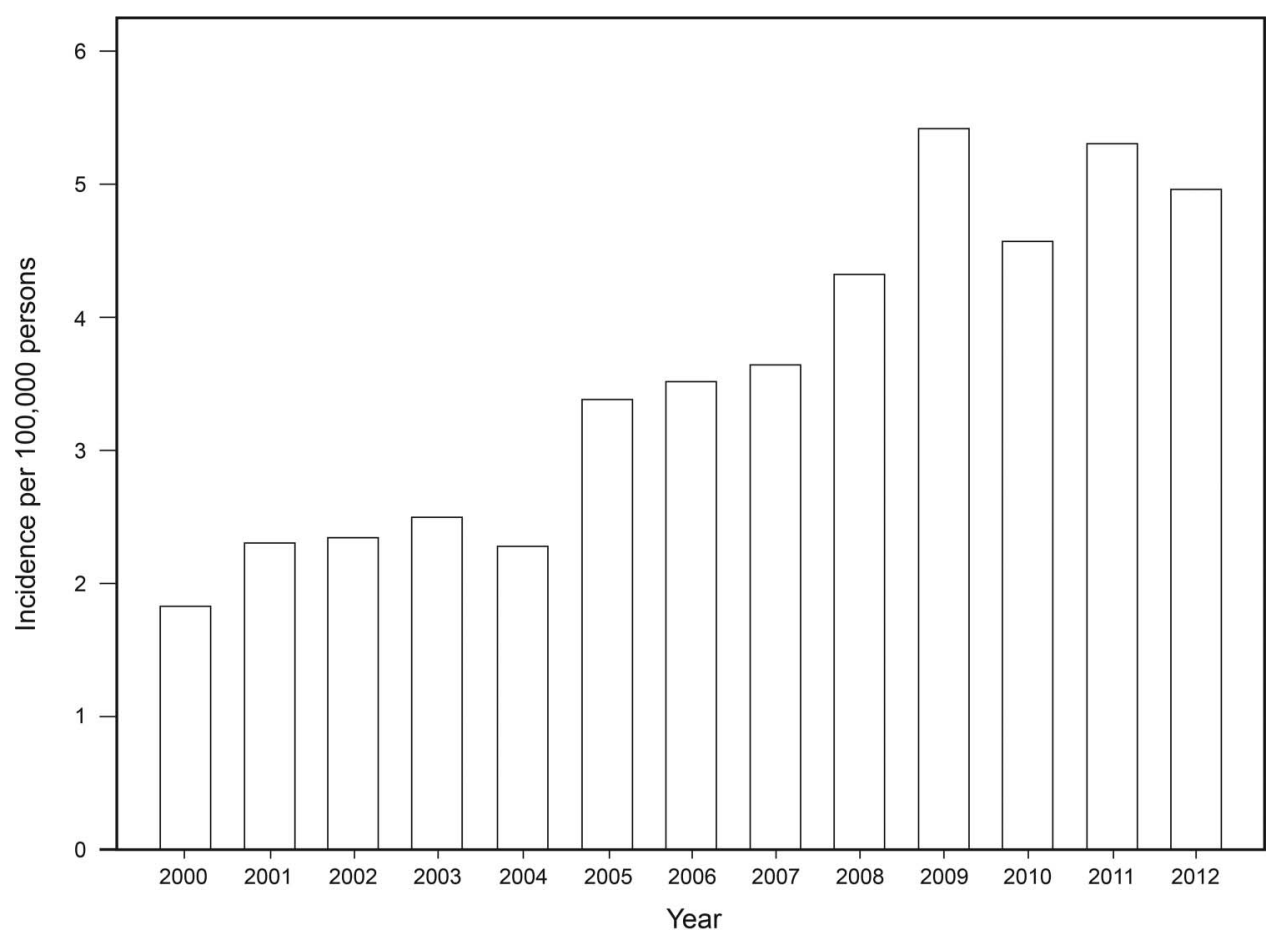

Fig. 1. Incidence of newly approved assistive device program ventilator applications per 100,000 adults $\geq 18$ y old. $P<.001$ for trend. Incidence was calculated as the number of new approvals/fiscal year/100,000 adults $\geq 18$ y old based on population.

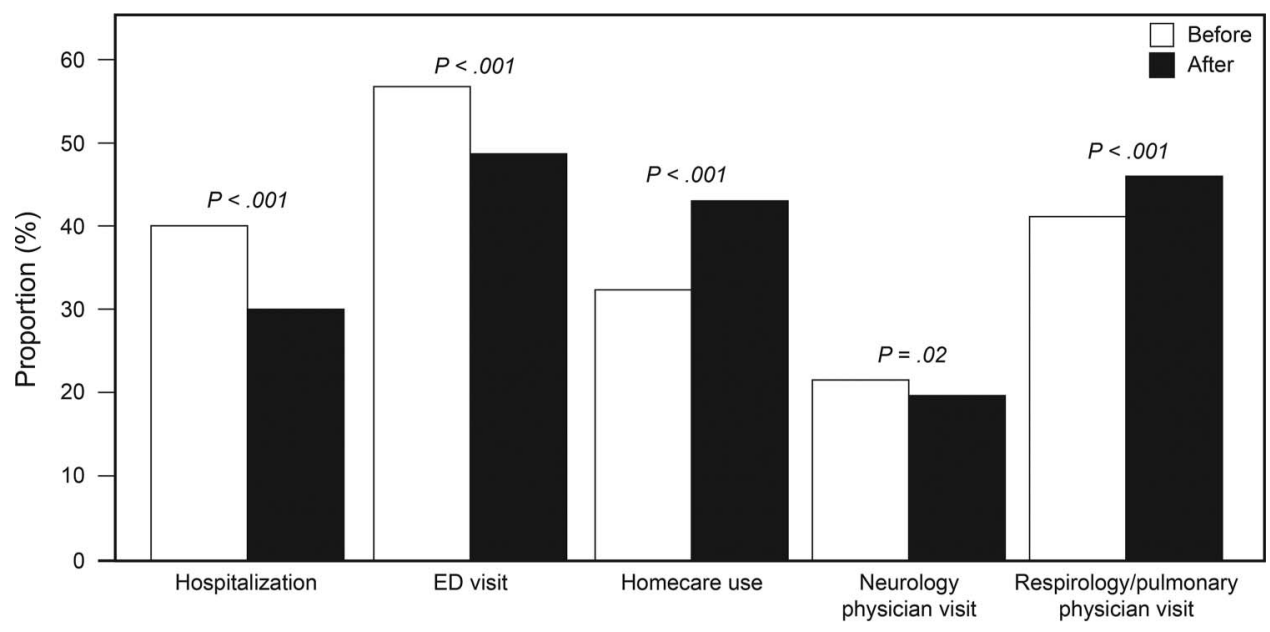

Fig. 2. Health services utilization in the year before and year after home mechanical ventilation approval. Health service utilization excludes $30 \mathrm{~d}$ before and after home mechanical ventilation approval. Use was calculated as a proportion of surviving cohort members who had that type of health-care contact. ED = emergency department.

been shown to be acceptable in previous studies, ${ }^{32,33}$ and this indicates that this approach has been adopted.

The reduction in hospitalizations (from 39.8 to $29.9 \%$ ) following home mechanical ventilation approval has been shown in cohort studies of individuals with neuromuscular disease ${ }^{5}$ or obesity. ${ }^{11,34}$ Our findings confirm this finding at a population-based level. This is relevant, given the resources that need to be invested to provide home mechanical ventilation in constrained health-care systems. The frequency of pulmonary medicine out-patient consultations for home mechanical ventilation users increased but remained low overall (41.8-47.0\%), which is concerning, since few other physicians have expertise in management of chronic respiratory failure requiring home mechanical ventilation. It is surprising that neurology consultations were found for only about 1 in 5 users, which is about half the proportion who had a neurological diagnosis. It may be that some respirologist/pulmonologists and neurologists are 
Table 2. 1- and 3-Year Mortality Trends After HMV Approval

\begin{tabular}{lcccc}
\hline \hline \multicolumn{1}{c}{ Age } & $2000-2003$ & $2004-2007$ & $2008-2012$ & $P$ \\
\hline 18-34 y & & & & \\
Approved, $n$ & 129 & 139 & 228 & \\
1-y mortality, \% & 8.5 & 8.6 & 8.3 & $>.99$ \\
3-y mortality, \% & 18.6 & 15.1 & 14.0 & .51 \\
35-64 y & & & & \\
Approved, $n$ & 417 & 669 & 1343 & .044 \\
1-y mortality, \% & 13.9 & 11.8 & 15.9 & .19 \\
3-y mortality, \% & 30.5 & 26.6 & 26.0 & \\
$\geq 65$ y & & & & \\
Approved, $n$ & 281 & 453 & 1011 & .75 \\
1-y mortality, \% & 24.6 & 26.9 & 25.5 & \\
3-y mortality, \% & 49.8 & 46.4 & 43.8 & .18 \\
& \multicolumn{5}{l}{} \\
Mortality proportions were compared with Pearson's chi-square test. \\
\hline
\end{tabular}

billing using internal medicine codes or that home mechanical ventilation is being managed by non-respiratory sleep physicians, intensive care physicians, or internists.

In our study, 1 and 3-y mortality varied by age strata, but there was little significant change over the 12-y period studied. Our mortality rates are consistent with the range of what has been reported previously. In individuals with ALS, 1- and 3-y mortality has been reported as 17.0-27.0 and $47.0-79.0 \%$, respectively, in individuals using home mechanical ventilation. ${ }^{35}$ Patients with less progressive conditions, such as obesity-hypoventilation syndrome, ${ }^{36}$ have been reported to have $10-20 \%$ mortality observed at $4 \mathrm{y}$ in home mechanical ventilation-treated individuals. The lack of change in mortality suggests that the indications and care for home mechanical ventilation users are similar across the time periods and that therapy options remain limited to prolong life for affected individuals.

There are several limitations to our study. First, in our cohort, we could not confirm the primary indication for home mechanical ventilation approvals, as the primary indication was not identifiable from administrative data. Therefore, using codes assigned for diagnoses arising from episodes of health-care utilization, we took a conservative approach and prioritized neuromuscular or thoracic cagerestricting conditions over COPD or lung disease. We made this choice because home mechanical ventilation use in COPD is discouraged in Canada. ${ }^{1}$ Notwithstanding Canadian guidelines, we found that $18.8 \%$ of our cohort had COPD without other indications for home mechanical ventilation initiation. Second, home mechanical ventilation adherence data were not available. Consequently, we were not able to determine the prevalence of home mechanical ventilation use within our cohort, although it is likely that most 1-y survivors were still using home mechanical ventilation. Third, we had to use the home mechanical ventilation approval date as a surrogate for a start date. Initiation of home mechanical ventilation may have predated the approval for hospitalized individuals if they were using an alternative non-government funded and short-term ventilator supplier to facilitate transition home. For those started as out-patients, therapy would follow soon after approval, since the home mechanical ventilation unit needs to be shipped and set up. Fourth, we did not assess trends in indications for home mechanical ventilation over time. These data may provide further explanation of the drivers of increasing incidence of home mechanical ventilation and should be explored in future studies. Fifth, we could not quantify the proportion of health-care utilization directly attributable to home mechanical ventilation opposed to that required for management of underlying disease and are therefore unable to comment on attributable costs of home ventilation.

\section{Conclusions}

The incidence of home mechanical ventilation use in Ontario has risen significantly; however, home mechanical ventilation users have lower rates of acute care health-care utilization. This suggests that home mechanical ventilation is having a positive impact on the health-care system. Areas for future study include elaborating on the reasons for the growth in home mechanical ventilation approvals by properly tracking new home mechanical ventilation starts, particularly the indication for therapy, as well as measuring patient follow-up and important outcomes prospectively. This may involve establishment of a registry of home mechanical ventilation users as well as leveraging existing technologies that allow monitoring of therapy adherence and efficacy.

\section{ACKNOWLEDGMENTS}

Parts of this material are based on data and information compiled and provided by the Canadian Institute for Health Information. However, the analyses, conclusions, opinions, and statements expressed herein are those of the authors and not necessarily those of the Canadian Institute for Health Information.

\section{REFERENCES}

1. McKim DA, Road J, Avendano M, Abdool S, Cote F, Duguid N, et al. Home mechanical ventilation: a Canadian Thoracic Society clinical practice guideline. Can Respir J 2011;18(4):197-215.

2. Windisch W, Walterspacher S, Siemon K, Geiseler J, Sitter H. Guidelines for non-invasive and invasive mechanical ventilation for treatment of chronic respiratory failure. Pneumologie 2010;64(10):640-652.

3. Make BJ, Hill NS, Goldberg AI, Bach JR, Criner GJ, Dunne PE, et al. Mechanical ventilation beyond the intensive care unit. Chest 1998;113(5):289S-344S.

4. Piper A, Flunt D, Wark P, Murray N, Brillante R, Laks L, et al. Domiciliary non-invasive ventilation in adult patients: a consensus statement. Intensive Care NSW; 2010. https://www.aci.health. nsw.gov.au/networks/intensive-care/intensive-care-manual/statewideguidelines/non-invasive-ventilation-guidelines. Accessed November 7, 2017. 


\section{Home Mechanical Ventilation in Canada}

5. Annane D, Orlikowski D, Chevret S. Nocturnal mechanical ventilation for chronic hypoventilation in patients with neuromuscular and chest wall disorders. Cochrane Database Syst Rev 2014;(12):CD001941.

6. Bourke SC, Tomlinson M, Williams TL, Bullock RE, Shaw PJ, Gibson GJ. Effects of non-invasive ventilation on survival and quality of life in patients with amyotrophic lateral sclerosis: a randomised controlled trial. Lancet Neurol 2006;5(2):140-147.

7. Eagle M, Baudouin SV, Chandler C, Giddings DR, Bullock R, Bushby K. Survival in Duchenne muscular dystrophy: improvements in life expectancy since 1967 and the impact of home nocturnal ventilation. Neuromuscul Disord 2002;12(10):926-929.

8. Huttmann SE, Windisch W, Storre JH. Invasive home mechanical ventilation: living conditions and health-related quality of life. Respiration 2015;89(4):312-321.

9. Masa JF, Corral J, Alonso ML, Ordax E, Troncoso MF, Gonzalez M, et al. Efficacy of different treatment alternatives for obesity hypoventilation syndrome: Pickwick Study. Am J Respir Crit Care Med. 2015;192(1):86-95.

10. Priou P, Hamel JF, Person C, Meslier N, Racineux JL, Urban T, Gagnadoux F. Long-term outcome of noninvasive positive pressure ventilation for obesity hypoventilation syndrome. Chest 2010;138(1):84-90.

11. Berg G, Delaive K, Manfreda J, Walld R, Kryger MH. The use of health-care resources in obesity-hypoventilation syndrome. Chest. 2001;120(2):377-383.

12. Struik FM, Sprooten RT, Kerstjens HA, Bladder G, Zijnen M, Asin J, et al. Nocturnal non-invasive ventilation in COPD patients with prolonged hypercapnia after ventilatory support for acute respiratory failure: a randomised, controlled, parallel-group study. Thorax 2014;69(9):826-834.

13. Köhnlein T, Windisch W, Köhler D, Drabik A, Geiseler J, Hartl S, et al. Non-invasive positive pressure ventilation for the treatment of severe stable chronic obstructive pulmonary disease: a prospective, multicentre, randomised, controlled clinical trial. Lancet Respir Med. 2014;2(9):698-705.

14. Murphy P, Arbane G, Bourke S, Calverley P, Dowson L, Duffy N, et al. Improving admission free survival with home mechanical ventilation (HMV) and home oxygen therapy (HOT) following life threatening COPD exacerbations: HoT-HMV UK trial NCT00990132. Eur Respir J. 2016;48:OA3527. doi: 10.1183/13993003.congress-2016.OA3527.

15. Lloyd-Owen SJ, Donaldson GC, Ambrosino N, Escarabill J, Farre R, Fauroux B, et al. Patterns of home mechanical ventilation use in Europe: Results from the Eurovent survey. Eur Respir J 2005;25(6):1025-1031.

16. Rose L, McKim DA, Katz SL, Leasa D, Nonoyama M, Pedersen C, et al. Home mechanical ventilation in Canada: a national survey. Respir Care 2015;60(5):695-704.

17. Leasa DJ, Elson S. Building a comprehensive system of services to support adults living with long-term mechanical ventilation. Can Respir J 2016:3985389. doi: 10.1155/2016/3185389.

18. Hannan LM, Sahi H, Road JD, McDonald CF, Berlowitz DJ, Howard ME. Care practices and health-related quality of life for individuals receiving assisted ventilation: a cross-national study. Ann Am Thorac Soc 2016;13(6):894-903.

19. Wise MP, Hart N, Davidson C, Fox R, Allen M, Elliott M, et al. Home mechanical ventilation. BMJ 2011;342:d1687-d1687.
20. Garner DJ, Berlowitz DJ, Douglas J, Harkness N, Howard M, McArdle $\mathrm{N}$, et al. Home mechanical ventilation in Australia and New Zealand. Eur Respir J 2013;41(1):39-45.

21. Benchimol EI, Smeeth L, Guttmann A, Harron K, Moher D, Petersen I, et al. The REporting of studies Conducted using Observational Routinely-collected health Data (RECORD) statement. PLoS Med 2015;12(10):e1001885.

22. Wilkins R. Postal Code Conversion File_Version 5. Ottawa; 2010. pp 1-68. http://odesi.scholarsportal.info/documentation/PCCF+/ V5F/MSWORD.PCCF5F.pdf

23. Quan H, Sundararajan V, Halfon P, Fong A, Burnand B, Luthi JC, et al. Coding algorithms for defining comorbidities in ICD-9-CM and ICD-10 administrative data. Med Care 2005;43(11):1130-1139.

24. Charlson M, Szatrowski TP, Peterson J, Gold J. Validation of a combined comorbidity index. J Clin Epidemiol 1994;47(11):1245-1251.

25. Charlson ME, Charlson RE, Peterson JC, Marinopoulos SS, Briggs WM, Hollenberg JP. The Charlson comorbidity index is adapted to predict costs of chronic disease in primary care patients. J Clin Epidemiol 2008;61(12):1234-1240.

26. Gershon AS, Wang C, Guan J, Vasilevska-Ristovska J, Cicutto L, To $\mathrm{T}$. Identifying individuals with physician diagnosed COPD in health administrative databases. COPD 2009;6(5):388-394.

27. Gershon AS, Wang C, Guan J, Vasilevska-Ristovska J, Cicutto L, To $\mathrm{T}$. Identifying patients with physician-diagnosed asthma in health administrative databases. Can Respir J 2009;16(6):183-188.

28. Tu JV, Chu A, Donovan LR, Ko DT, Booth GL, Tu K, et al. The Cardiovascular Health in Ambulatory Care Research Team (CANHEART): using big data to measure and improve cardiovascular health and healthcare services. Circ Cardiovasc Qual Outcomes. 2015; 8(2):204-212.

29. Scales DC, Guan J, Martin CM, Redelmeier DA. Administrative data accurately identified intensive care unit admissions in Ontario. J Clin Epidemiol 2006;59(8):802-807.

30. Gotay CC, Katzmarzyk PT, Janssen I, Dawson MY, Aminoltejari K, Bartley NL. Updating the Canadian obesity maps: an epidemic in progress. Can J Public Health 2012;104(1):e64-e68.

31. Ambrosino N, Carpenè N, Gherardi M. Chronic respiratory care for neuromuscular diseases in adults. Eur Respir J. 2009;34(2):444-451.

32. Chatwin M, Nickol AH, Morrell MJ, Polkey MI, Simonds AK. Randomised trial of inpatient versus outpatient initiation of home mechanical ventilation in patients with nocturnal hypoventilation. Respir Med 2008;102(11):1528-1535.

33. Jaye J, Chatwin M, Dayer M, Morrell MJ, Simonds AK. Autotitrating versus standard noninvasive ventilation: a randomised crossover trial. Eur Respir J 2009;33(3):566-571.

34. Povitz M, Tsai WH, Pendharkar SR, Hanly PJ, James MT. Healthcare use in individuals with obesity and chronic hypoxemia treated for sleep disordered breathing. J Clin Sleep Med 2016;12(4):543-548.

35. Dreyer P, Lorenzen CK, Schou L, Felding M. Survival in ALS with home mechanical ventilation non-invasively and invasively: a 15year cohort study in west Denmark. Amyotroph Lateral Scler Frontotemporal Degener 2014;15(1):62-67.

36. Pépin JL, Borel JC, Janssens JP. Obesity hypoventilation syndrome: an underdiagnosed and undertreated condition. Am J Respir Crit Care Med 2012;186(12):1205-1207.

This article is approved for Continuing Respiratory Care Education credit. For information and to obtain your CRCE

(free to AARC members) visit www.rcjournal.com

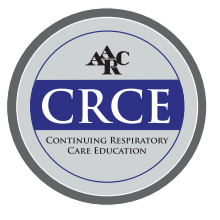

